\title{
USING THE GETTY VOCABULARIES TO CONNECT RESOURCES IN A LINKED AND OPEN WORLD: GROWING POTENTIAL THROUGH CONTRIBUTIONS
}

\author{
J. Cobb * \\ (Keynote) \\ The J. Paul Getty Trust (Getty Digital division, Department of Collection and Content Management Systems), 1200 Getty Center Drive, \\ Suite 200, Los Angeles, CA 90049, USA - JCobb@getty.edu
}

\begin{abstract}
The J. Paul Getty Trust is a cultural and philanthropic institution dedicated to the presentation, conservation, and interpretation of the world's artistic legacy.

Through the collective and individual work of its constituent programs - the Getty Conservation Institute, the Getty Foundation, the J Paul Getty Museum, and the Getty Research Institute - the Getty pursues its mission in Los Angeles and throughout the world, serving both the general interested public and a wide range of professional communities in order to promote a vital civil society through an understanding of the visual arts.

The Getty Research Institute is dedicated to furthering knowledge and advancing understanding of the visual arts and their various histories through its expertise, active collecting program, public programs, institutional collaborations, exhibitions, publications, digital services, and residential scholars programs. Its Research Library and Special Collections of rare materials and digital resources serve an international community of scholars and the interested public.
\end{abstract}

The Institute's activities and scholarly resources guide and sustain each other and together provide a unique environment for research, critical inquiry, and scholarly exchange.

The Getty Vocabularies have been produced and maintained for decades by the Getty Vocabulary Program, which is part of the Getty Research Institute (GRI).

They are compliant with ISO and NICO standards for multilingual thesaurus construction and contain terminology and other information about people, places, objects, and art-historical and conservation concepts.

They are compiled resources and grow through contributions from various Getty projects and from many external institutions.

Although there are now five vocabularies, this talk will concentrate on the three that have been released as Linked Open Data.

They are the Art \& Architecture Thesaurus (AAT)®, the Union List of Artist Names (ULAN)®, and the Getty Thesaurus of Geographic Names $(T G N) \mathbb{R}$. These three vocabularies were the first to be released because they are used universally in the cultural heritage and library communities and represent best practice.

The presentation will show examples of how AAT, TGN and ULAN are used and to highlight reasons why they have become such valuable resources. It will provide an overview of some of the major challenges and lessons learned since the vocabularies were made available as LOD.

Topics will range from reconciling external resources with the Getty vocabularies to strategies for cultural heritage organizations to contribute new concepts and terminology and the need to easily and quickly provide contributors with the information they need to insert the link into their collection management systems.

The goal is not only to work with the community to help everyone make the best use of the LOD datasets, but to make sure the datasets themselves continue to grow through contributions.

\section{References}

The J. Paul Getty Trust - http://www.getty.edu/

* Keynote of the GEORES2019 conference 
The International Archives of the Photogrammetry, Remote Sensing and Spatial Information Sciences, Volume XLII-2/W11, 2019 GEORES 2019 - 2nd International Conference of Geomatics and Restoration, 8-10 May 2019, Milan, Italy

Getty Vocabularies - http://www.getty.edu/research/tools/vocabularies/index.html AATA Online - http://aata.getty.edu/Home

Arches - https://www.archesproject.org 